\title{
NOTES
}

\section{Polycondensation of Diethyl Mucate with Hexamethyl- enediamine in the Presence of Poly(4-hydroxystyrene)}

\author{
Naoya Ogata, Kohei SANui, Masakazu YoshiKaWA, \\ and Yumi SAIGOU \\ Department of Chemistry, Faculty of Science and Technology, Sophia University, \\ 7-1 Kioi-cho, Chiyoda-ku, Tokyo 102, Japan
}

(Received May 8, 1985)

\begin{abstract}
KEY WORDS Polycondensation Reaction / Matrix Polycondensation / Matrix Polymer / Poly(4-hydroxystyrene) /
\end{abstract}

It was reported ${ }^{1}$ that the rate of the polycondensation of dimethyl tartarate (DMT) with hexamethylenediamine (HMD) was enhanced by the presence of polymer matrices such as poly(1-vinylpyrrolidone), a polysaccharide, or poly(vinyl alcohol). This rate enhancement was due to the hydrogen-bonding interaction between DMT or the resulting polyamide with the matrix polymers so that monomers were adsorbed along the chains of the matrix polymers, thus increasing the local concentration of monomers at the reaction stage of the polycondensation. The presence of poly(4-vinylpyridine) did not enhance the rate of the polycondensation of diethyl mucate (DEM) with HMD, but the molecular weight of the resulting polyamide increased. ${ }^{2}$

This paper deals with the polycondensation of diethyl mucate (DEM) with hexamethylenediamine(HMD) in the presence of a matrix polymer which may adsorb DEM by interactions with carbonyl or hydroxyl moieties in DEM so that polycondensation reactions may take place along the chains of the matrix polymer.

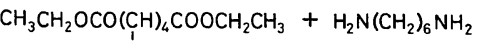

$$
\begin{aligned}
& \mathrm{OH} \text { (DEM) (HMD) } \\
& \underset{\substack{\text { in DOX or in DMSO } \\
\text { at } 60^{\circ} \mathrm{C}}}{\stackrel{\mathrm{CO}(\mathrm{CH})_{4} \mathrm{CONH}\left(\mathrm{CH}_{2}\right)_{6} \mathrm{NH}}{\mathrm{OH}}}+2 \mathrm{CH}_{3} \mathrm{CH}_{2} \mathrm{OH}
\end{aligned}
$$

\section{EXPERIMENTAL}

Diethyl mucate (DEM) and diethyl adipate (DEAd) were synthesized by esterification of commercially available diacids and ethanol. Polycondensation of these diesters with HMD was carried out in dimethyl sulfoxide (DMSO) or 1,4-dioxane (DOX) in the presence or absence of the matrices shown below by a conventional polycondensation method at $60^{\circ} \mathrm{C}$. The added amount of matrices was adjusted according to the concentration of repeating unit based on the amount of ester moiety in DEM. The following polymers were added as the matrix polymers:

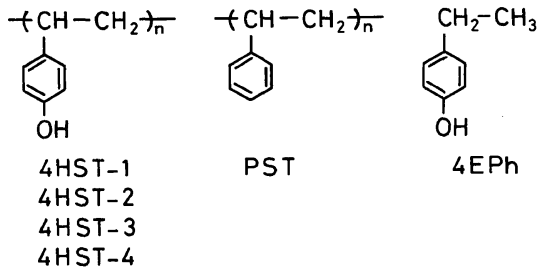

\begin{tabular}{ll}
\hline Matrix & $\eta_{\text {sp }} / c^{\mathrm{a}}$ \\
\hline 4HST-1 & 0.08 \\
4HST-2 & 0.09 \\
4HST-3 & 0.14 \\
4HST-4 & 0.34 \\
PST & 0.67 \\
\hline
\end{tabular}

a $0.01 \mathrm{~g} / 10 \mathrm{~cm}^{3}$ in $\mathrm{CHCl}_{2} \mathrm{COOH}$ at $30^{\circ} \mathrm{C}$. 
The rates of polycondensation were followed by titrating the residual amount of HMD in the solution. The polycondensation was initiated by mixing a solution of HMD with that of DEM and matrices, and the mixture was allowed to stand overnight in order to reach an equilibrium and form a complex between DEM with the matrices. Separation of polyamide from the matrix was carried out by extracting the matrix polymer with methanol in a Soxhlet extractor. The apparent rate constants of the present matrix polycondensation were calculated as secondordered reactions.

\section{RESULTS AND DISCUSSION}

Figures 1 and 2 show the polycondensation of DEM with HMD in DMSO or DOX in the presence or absence of a matrix at $60^{\circ} \mathrm{C}$. The rate of the polycondensation in the presence of 4HST-4 was greater than that in the presence of $4 \mathrm{EPh}$ or absence of a matrix. It was also found that rate enhancement due to $4 \mathrm{HST}-4$ in DOX was more pronounced than that in DMSO. This result suggests that the rate enhancement effect might be attributed to a hydrogen-bonding interaction.

The following three interactions are thought to be possible hydrogen-bonding interactions: (1) the interaction between hydroxyl groups in 4HST and carbonyl moieties in DEM; (2) that between hydroxyl groups in 4HST and hydroxyl groups in DEM; (3) that between hydroxyl groups in 4HST and amino groups in HMD. We at first investigated the role of hydroxyl groups in the matrix (4HST). Figure 2 clearly shows that hydroxyl groups in 4HST play an important role as binding sites for monomers since the polycondensation in the presence of PST took place at almost the same rate as that in the absence of the matrix.

Secondly, we investigated the effects of the hydroxyl and carbonyl moieties in DEM. The reseluts are shown in Figure 3. Polycondensation of diethyl adipate was also enhanced in

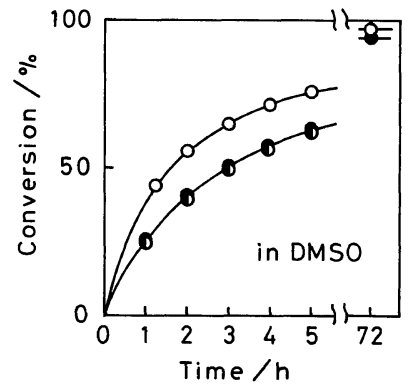

Figure 1. Time-conversion curves of the matrix polycondensation of DEM with HMD at $60^{\circ} \mathrm{C}$. O, 4HST-4; D, $4 \mathrm{EPh}$;, none; $[$ monomer $]=0.05 \mathrm{~mol} \mathrm{dm}^{-3}$; $[$ matrix $]=0.10 \mathrm{~mol} \mathrm{dm}^{-3}$ or unit $\mathrm{mol} \mathrm{dm} \mathrm{d}^{-3}$.

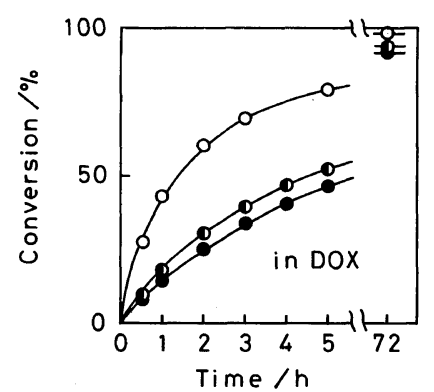

Figure 2. Time-conversion curves of the matrix polycondensation of DEM with $\mathrm{HMD}$ at $60^{\circ} \mathrm{C}$. $\mathrm{O}$, 4HST4; D, PST; O, none; [monomer] $=0.05 \mathrm{~mol} \mathrm{dm}^{-3}$; $[$ matrix $]=0.10$ unit $\mathrm{mol} \mathrm{dm}^{-3}$.

\begin{tabular}{|c|c|c|c|}
\hline \multirow{2}{*}{ Matrix } & $k_{1}$ & Matrix & Polyamide \\
\hline & $\mathrm{mol}^{-1} \mathrm{dm}^{3} \mathrm{~s}^{-1}$ & $\eta_{\mathrm{sp}} / c^{\mathrm{a}}$ & $\eta_{\mathrm{sp}} / c^{\mathrm{a}}$ \\
\hline None & 2.5 & - & 0.27 \\
\hline 4HST-4 & 15.9 & 0.34 & 0.32 \\
\hline PST & 2.5 & 0.30 & 0.27 \\
\hline
\end{tabular}

a $0.01 \mathrm{~g} / 10 \mathrm{~cm}^{3}$ in $\mathrm{CHCl}_{2} \mathrm{COOH}$ at $30^{\circ} \mathrm{C}$.

the presence of 4HST-4 in spite of the fact that diethyl adipate has no hydroxyl group. If the hydroxyl group in DEM contributes to rate enhancement, results such as shown in Figure 3 would not be observed. From this point, we concluded that the carbonyl moiety in DEM plays a role as a binding site for a hydrogenbonding interaction.

DEM was concentrated around the matrix by the hydrogen-bonding interaction between 


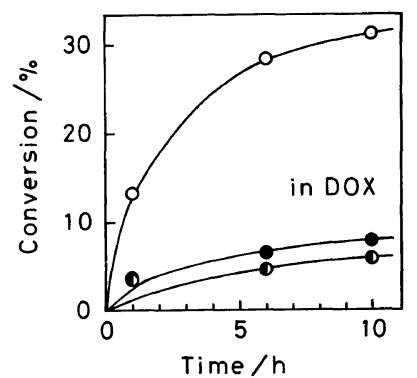

Figure 3. Matrix polycondensation of DEAd with $\mathrm{HMD}$ at $60^{\circ} \mathrm{C}$. $\mathrm{O}, 4 \mathrm{HST}-4 ;-4 \mathrm{EPh} ; 0$, none; [monomer] $=0.05 \mathrm{~mol} \mathrm{dm}^{-3} ; \quad[$ matrix $]=0.10 \mathrm{~mol} \mathrm{dm}^{-3}$ or unit $\mathrm{moldm}^{-3}$.

the carbonyl moiety in DEM and the hydroxyl group in 4HST before the start of polycondensation. As a result, the rate enhancement and increase of molecular weight of the corresponding polyamide were observed. At present, we conclude that the hydrogen-bonding interaction between hydroxyl groups in matrix (4HST) and carbonyl moieties in DEM is the dominant interaction to enhance the polycondensation rate of DEM with HMD in the presence of 4HST matrix.

Lastly, Figure 4 shows the effect of the degree of polycondensation of the matrix polymer on the polycondensation reaction of DEM with HMD, where the viscosity of the matrix polymer is used as a measure of the degree of polymerization. Increase of viscosity values of the matrix polymer (4HST) induced both an increase of the reaction rate and viscosity of the corresponding polyamide as shown in Figure 4. Increase of the polymer length might cause more hydrophobic environment around the hydroxyl group in the matrix, and such increased hydrophobicity strengthened the hydrogen-bonding interaction, leading to an increase in the local concentrations of DEM. As a result, the polycondensation rate was increased. Further, the longer

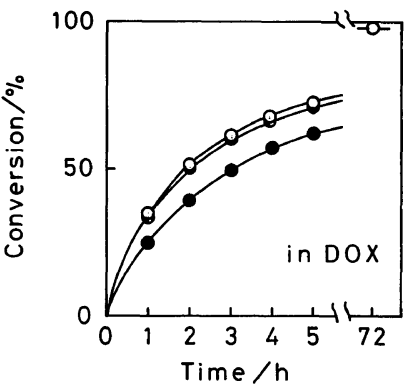

Figure 4. Time-conversion curves of the matrix polycondensation of DEM with $\mathrm{HMD}$ at $60^{\circ} \mathrm{C}$., $4 \mathrm{HST}$ 1; D, 4HST-2; O, 4HST-3; [monomer] $=0.05 \mathrm{~mol} \mathrm{dm}^{-3}$; [matrix] $=0.10$ unit mol dm ${ }^{-3}$.

\begin{tabular}{|c|c|c|c|}
\hline \multirow{2}{*}{ Matrix } & $k_{1}$ & Matrix & Polyamide \\
\hline & $\mathrm{mol}^{-1} \mathrm{dm}^{3} \mathrm{~s}^{-1}$ & $\eta_{\mathrm{sp}} / c^{\mathrm{a}}$ & $\eta_{\mathrm{sp}} / c^{\mathrm{a}}$ \\
\hline 4HST-1 & 6.5 & 0.08 & 0.16 \\
\hline 4HST-2 & 10.1 & 0.09 & 0.21 \\
\hline 4HST-3 & 10.4 & 0.14 & 0.31 \\
\hline 4HST-4 & 15.9 & 0.34 & 0.32 \\
\hline
\end{tabular}

a $0.01 \mathrm{~g} / 10 \mathrm{~cm}^{3}$ in $\mathrm{CHCl}_{2} \mathrm{COOH}$ at $30^{\circ} \mathrm{C}$.

the matrix polymer, the longer the monomer, DEM, might line up along the matrix polymer. This well lined-up monomer sequence might cause an increase of viscosity of the corresponding polyamide.

Thus it was found in this work that the polycondensation of DEM with HMD was enhanced in the presence of a matrix polymer, and the longer the matrix polymer, the longer was the corresponding polyamide obtained. This matrix effect might be due to hydrogenbonding interactions.

\section{REFERENCES}

1. N. Ogata, K. Sanui, H. Nakamura, and $\mathbf{M}$. Kuwahara, J. Polym. Sci., Polym. Chem. Ed., 18, 939 (1980).

2. N. Ogata, K. Sanui, and H. Nakamura, J. Polym. Sci., Polym. Chem. Ed., 18, 933 (1980). 